\title{
A PRODUÇÃO ACADÊMICO-CIENTÍFICA DO PROGRAMA DE PÓS- GRADUAÇẪO EM EDUCAÇÃO DA UNESP/MARÍLIA-SP E A POLÍTICA PÚBLICA NACIONAL DE EDUCAÇÃO ESPECIAL NO BRASIL: ASPECTOS HISTÓRICOS
}

\author{
LA PRODUCCIÓN ACADÉMICO-CIENTÍFICADA PROGRAMA DE POSGRADO \\ EN EDUCACIÓN DE LA UNESP/MARÍLIA-SP Y LA POLÍTICA PÚBLICA \\ NACIONAL DE EDUCACIÓN ESPECIAL EN BRASIL: ASPECTOS \\ HISTÓRICOS
}

\section{THE ACADEMIC-SCIENTIFIC PRODUCTION POST-GRADUATION PROGRAM IN EDUCATION OF UNESP/MARÍLIA-SP AND THE NATIONAL PUBLIC POLICY OF SPECIAL EDUCATION IN BRAZIL: HISTORICAL ASPECTS}

\author{
Maria Silvia Rosa SANTANA ${ }^{1}$ \\ Rosane Michelli de CASTRO ${ }^{2}$ \\ Elieuza Aparecida de LIMA $^{3}$
}

RESUMO: Apresentam-se neste artigo resultados das nossas reflexões realizadas junto aos grupos de estudos e pesquisas que integramos, centradas no objetivo geral de sistematizar e analisar teses e dissertações concluídas entre 2005 e 2008, na linha de pesquisa "Educação Especial no Brasil”, do Programa de Pós-Graduação em Educação da FFC-UNESP/Marília. Tais reflexões foram realizadas considerando-se que as mudanças, políticas públicas voltadas para as várias áreas sociais, assim como à educação são ou deveriam ser impulsionadas também pelos resultados das pesquisas acadêmico-científicas. Nesse sentido, e após as investigações realizadas, concluímos que as teses e dissertações analisadas foram capazes de apontar e legitimar, pelo existente ou o lacunar, aspectos das lutas que se travaram em Educação Especial no Brasil numa perspectiva inclusiva, as quais culminaram na Política Nacional de Educação Especial e nosso país.

PALAVRAS-CHAVE: Educação. História da educação. Educação especial. Produção acadêmico-científica. Política Nacional de Educação Especial no Brasil.

\footnotetext{
${ }^{1}$ Universidade Estadual de Mato Grosso do Sul (UEMS), Paranaíba - MS - Brasil. Professora Doutora junto aos Cursos de Pedagogia e de Ciências Sociais da Universidade Estadual de Mato Grosso do Sul UEMS/Unidade Universitária de Paranaíba-MS, e ao Curso de Pós-Graduação lato sensu em Educação e em Direitos Humanos e Programa de Pós-Graduação em Educação. ORCID <https://orcid.org/00000002-2147-8279>. E-mail: mariaros_664@hotmail.com

${ }^{2}$ Universidade Estadual Paulista (UNESP), Faculdade de Filosofia e Ciências (FFC), Marília - SP Brasil. Professora Assistente Doutora junto ao Departamento de Didática e ao Programa de PósGraduação em Educação. ORCID <https://orcid.org/0000-0002-7383-4810>. E-mail: r.castro@unesp.br ${ }^{3}$ Universidade Estadual Paulista (UNESP), Faculdade de Filosofia e Ciências (FFC), Marília - SP Brasil. Professora Assistente Doutora junto ao Departamento de Didática e ao Programa de PósGraduação em Educação da UNESP. ORCID <https://orcid.org/0000-0002-4957-6356>. E-mail: aelislima2013@gmail.com
} 
RESUMEN: Se presentan en este artículo resultados de nuestras reflexiones realizadas junto a los grupos de estudios e investigaciones que integramos, centradas en el objetivo general de sistematizar y analizar tesis y disertaciones concluidas entre 2005 y 2008, en la línea de investigación "Educación Especial en Brasil", del Programa de Postgrado en Educación de la FFC-Unesp / Marília. Tales reflexiones se realizaron considerando que los cambios, políticas públicas dirigidas a las diversas áreas sociales, así como a la educación, son o deberían ser impulsadas también por los resultados de las investigaciones académico-científicas. En ese sentido, y después de las investigaciones realizadas, concluimos que las tesis y disertaciones analizadas fueron capaces de apuntar y legitimar, por lo existente o lo lacunar, aspectos de las luchas que se trabaron en Educación Especial en Brasil en una perspectiva inclusiva, las cuales culminaron en la Política Nacional de Educación Especial y nuestro paí.

PALABRAS CLAVE: Educación. Historia de la educación. Educación especial. Producción académica-científica. Política Nacional de Educación Especial en Brasil

ABSTRACT: This article presents results of our reflections carried out with the groups of studies and research that we integrate, focusing on the general objective of systematizing and analyzing theses and dissertations concluded between 2005 and 2008, in the line of research "Special Education in Brazil", Program of PostGraduation in Education of the FFC-Unesp / Marilia. Such reflections were carried out considering that the changes, public policies aimed at the various social areas, as well as education are or should be boosted also by the results of academic-scientific research. In this sense, and after the investigations carried out, we conclude that the analyzed theses and dissertations were capable of pointing out and legitimizing, by the existent or the no, aspects of the struggles that were fought in Special Education in Brazil in an inclusive perspective, which culminated in the National Policy of Special Education and our country.

KEYWORDS: Education. History of education. Special education. Academic-scientific production. National Policy on Special Education in Brazil.

\section{Introdução}

O ano de 2008, no Brasil, pode ser considerado como marco importante para o estabelecimento de diretrizes para a criação de políticas públicas e práticas pedagógicas voltadas à inclusão escolar de crianças com deficiências. Nesse ano, o Ministério da Educação (MEC) lançou a Política Nacional de Educação Especial na perspectiva da Educação Inclusiva, a qual prevê, dentre outras contribuições o estabelecimento do atendimento educacional especializado - AEE. Não nos atemos, neste artigo, na discussão de seus aspectos, mesmo porque não foi este nosso objetivo. Mas, buscaremos apresentar reflexões em torno das contribuições para a aprovação dessa lei, da produção acadêmico-científica de um programa de pós-graduação em educação - Programa de Pós-Graduação em Educação da UNESP/Câmpus de Marília - Faculdade de Filosofia, 
Ciências e Letras - centralmente, da linha de pesquisa "Educação Especial no Brasil", em busca de antecedentes históricos dessa Política Nacional de 2008, a qual, neste 2018, completa seus 10 anos no Brasil.

No movimento e tensões na elaboração de políticas públicas nas várias áreas sociais, não estamos a desconsiderar as forças que estão, no todo, a se relacionar. Segundo Boneti (2003, p. 15), uma política pública é "[...] a ação que nasce do contexto social, mas que passa pela esfera estatal como decisão de intervenção pública numa realidade, quer ela seja econômica ou social". Mas, e igualmente, concordamos com as afirmações de Melo e Silva (2016 p. 156), de que

[...] os intelectuais [e sua produção com fomento de agências financiadoras] são fundamentais na efetivação ou não das políticas públicas, entendidas como mecanismos de organização social que estão presentes nos programas políticos a serem implementados em uma gestão. (SCHLESENER, 2009).

Nesse sentido, mediante um levantamento bibliográfico realizado com o objetivo de identificar e reunir estudos e pesquisas realizadas, no mesmo recorte de tempo, por outras instituições de ensino superior e, até mesmo, por outros pesquisadores da própria UNESP, sobre análises de produções da Pós-Graduação na área de Educação Especial, foi possível constatarmos que há relevante produção acadêmica a respeito.

Segundo Nunes, Ferreira e Mendes (2003), um grupo de pesquisadores coordenado por Dias e Goyos (DIAS; GOYOS; FERRARI; DALL'ALBA; SANTOS; OMOTE, 1987 apud NUNES; FERREIRA; MENDES, 2003) desenvolveram um trabalho pioneiro ao analisarem os resumos de 38 dissertações defendidas no Programa de Pós-Graduação em Educação Especial da Universidade Federal de São Carlos, entre 1981 e 1987.

Também, outro grupo de pesquisadores coordenado por Leila R. D' Oliveira de P. Nunes e Rosana Glat (UERJ), Júlio R. Ferreira (Unicamp) e Enicéia Gonçalves Mendes (UFSCar), iniciaram em 1995 um projeto de análise da produção discente (PRODISC), que foi desenvolvido em quatro versões e englobando vários programas de pós-graduação, dentre os quais: Programa de Pós-Graduação em Educação da Universidade do Estado do Rio de Janeiro (PROPEd/UERJ) e 22 programas de pósgraduação em Educação reconhecidos à época pelo Ministério da Educação e Cultura MEC. 
Em 2003, Nunes et al (2003) e Nunes, Ferreira e Mendes (2003) analisaram dissertações e teses em Educação Especial, no período entre 1981 a 2001. Nunes et al (2003) apontaram que 27 universidades realizaram trabalhos na área de Educação Especial e ressaltaram que duas universidades (UFSCar e UERJ) se destacaram entre as demais no que se refere ao número de trabalhos concluídos.

Silva (2004) desenvolveu sua pesquisa no âmbito do Programa de PósGraduação em Educação Especial da UFSCar, tendo como objeto de análise as dissertações e teses defendidas nesse Programa, entre 1981 e 2002.

Também em 2006, Manzini et al desenvolveu analise das dissertações e teses em Educação Especial produzidas no Programa de Pós-graduação em Educação durante o período de 1993 a 2004, fazendo um mapeamento sobre os temas, tipo de deficiência enfocada, abordagens metodológicas utilizadas em trabalhos sobre Educação Especial, dentre outras informações. Considerando a existência da análise desenvolvida por Manzini et al (2006), tendo como corpus as teses e dissertações vinculadas à linha de pesquisa "Educação Especial no Brasil" e defendidas também no Programa de PósGraduação em Educação da FFC-Unesp/Marília, porém entre 1994 e 2004, consideramos pertinente proceder a um recorte temporal para o desenvolvimento do projeto de pesquisa, com marco inicial em 2005. O marco final desse recorte foi o ano de 2008, período esse contemplado na pesquisa de Castro (2009a), à qual nossas investigações estiveram vinculadas e, para este artigo, e considerando-se que esse foi o período imediatamente anterior à importantes reformas da Educação Especial no Brasil, na perspectiva inclusiva.

Nesse sentido, para a recuperação dos dados e informações que serviram de base para o desenvolvimento do projeto de pesquisa, foi utilizado, primeiramente, o instrumento de pesquisa elaborado por Castro (2009b) Teses e dissertações do programa de pós-graduação em educação da FFC-Unesp/Marília, produzidas entre 1992-2008. Isso porque, nesse instrumento elaborado por Castro (2009b) as teses e dissertações mencionadas, vinculadas a todas as linhas do Programa em questão, encontram-se sistematizadas mediante os seguintes aspectos: referência, palavras-chave, linha de pesquisa à qual se vincula e resumo informado pelo autor. Segundo Bellotto (1979, p. 133), o instrumento de pesquisa se caracteriza como uma das "[...] vias de acesso do historiador ao documento, sendo a chave da utilização dos arquivos como fontes primárias da História”. 
Desse instrumento elaborado por Castro (2009b), selecionamos as teses e dissertações vinculadas à linha "Educação Especial no Brasil", com todos os seus aspectos sistematizados. Feito isso, elaboramos novo instrumento de pesquisa, agora sistematizado com os aspectos das teses e dissertações selecionadas, pertinentes para o alcance dos objetivos propostos, a saber: títulos, palavras-chave, objetivos, material, método e procedimentos de análise dos resultados das pesquisas e principais considerações finais ou conclusões dos estudos e pesquisas. Cabe-nos ressaltar, assim como afirmou Castro (2009c), que tal trabalho de sistematização foi penalizado devido à pouca consistência de dados ou a má elaboração de muitos resumos das teses e dissertações, pelos próprios pesquisadores. E, considerando-se que muitas pesquisas, sobretudo as do tipo "estado da arte", o insumo principal de análise são os resumos da produção acadêmico-científica sobre o que se está a estudar, é imprescindível que os pesquisadores sejam rigorosos na sua elaboração, como se exige os trabalhos de natureza acadêmico-científicos.

Para a identificação de possíveis indicadores contidos no objetivo das nossas investigações, acerca das contribuições das pesquisas vinculados à linha "Educação Especial no Brasil", realizamos uma análise de informações presentes nas referências das teses e dissertações produzidas sob a ementa em vigor, desde 1999, da linha de pesquisa "Educação Especial no Brasil":

\footnotetext{
Ocupa-se do estudo das características das pessoas portadoras de necessidades especiais no contexto educativo e da construção de alternativas pedagógicas inclusivas, desde seus fundamentos até os aspectos ergonômicos e particulares do ensino destinado a esse público, pesquisando especificamente: a) a inclusão escolar e a formação de recursos humanos em Educação Especial; b) os fundamentos da pedagogia inclusiva; c) a ergonomia e o mobiliário adaptado; d) a adaptação nas atividades e nos recursos; e) os recursos alternativos e suplementares de comunicação em Educação Especial; f) o ensino do deficiente e a sua profissionalização; g) Pesquisa e Produção do conhecimento em Educação Especial. (CASTRO, 2010, p. 81).
}

Assim, foi possível classificarmos o conjunto de teses e dissertações vinculadas a essa linha de pesquisa, concluídas entre 2005 e 2008, mediante os seguintes eixos temáticos, como veremos adiante.

Considerando-se os nossos objetivos e a perspectiva adotada para o desenvolvimento da pesquisa, nossas investigações caracterizaram-se como documental, quanto às fontes, e histórica, quanto à abordagem. 
Ainda, considerando-se que se tratou de um corpus documental vasto e os limites espaciais deste artigo, estamos certas de que a análise realizada possui mais um caráter descritivo e cumulativo das informações e dados obtidos do que propriamente interpretativo, o que, buscamos realizar, ainda que brevemente, em “Conclusões".

\section{Apresentação e discussão dos dados}

Seguem as referências das teses e dissertações concluídas entre 2005 a 2008, na linha de pesquisa "Educação Especial no Brasil", do Programa de Pós-Graduação em Educação da UNESP/Câmpus de Marília - PPGE da Faculdade de Filosofia e Ciências - FFC.

Quadro 1 - Referências das teses e dissertações desenvolvidas, entre 2005 e 2008, na linha de pesquisa Educação Especial no Brasil do PPGE-FFC/UNESP-Marília

SILVA, Andréia Parente. Análise das falas dos professores de educação especial a respeito da atuação e da formação do educador relacionado ao contexto da comunicação. 2005. 179 f. Dissertação (Mestrado em Educação). Universidade Estadual Paulista Júlio de Mesquita Filho/Marília, 2005.

BRUNO, Marilda de Moraes Garcia. Avaliação educacional de alunos com baixa visão e múltipla deficiência na educação infantil: Uma proposta de adaptação e elaboração de instrumentos. 2005. 157f. Tese (Doutorado em Educação). Universidade Estadual Paulista Júlio de Mesquita Filho/Marília, 2005.

AUDI, Mauro. Estudo comparativo do comportamento motor de membro superior em encefalopatias que fazem uso de pulseira estabilizadora. 2006. 112f. Dissertação (Mestrado em Educação). Universidade Estadual Paulista Júlio de Mesquita Filho/Marília, 2006.

FERREIRA, Grace Cristina. Programa de educação familiar continuada em linguagem: orientações a pais de crianças com atrasos globais do desenvolvimento. 2006. $165 \mathrm{f}$. Dissertação (Mestrado em Educação). Universidade Estadual Paulista Júlio de Mesquita Filho/Marília, 2006.

ALVES, Vanessa Aparecida. Análise das modalidades expressivas de um aluno não-falante frente a diferentes interlocutores durante situação de jogo. 2006. 170f. Dissertação (Mestrado em Educação). Universidade Estadual Paulista Júlio de Mesquita Filho/Marília, 2006.

SAMESHIMA, Fabiana Sayuri. Habilidades expressivas de um grupo de alunos não-falantes durante atividades de jogos. 2006. 104f. Dissertação (Mestrado em Educação). Universidade Estadual Paulista Júlio de Mesquita Filho/Marília, 2006.

MONTEIRO, Ana Paula Hungaro. Há mudanças nas concepções do professor do ensino fundamental em relação à inclusão após a inserção de alunos deficientes? 2006. 163f. Dissertação (Mestrado em Educação). Universidade Estadual Paulista Júlio de Mesquita Filho/Marília, 2006.

REGANHAN, Walkiria Gonçalves. Recursos e estratégias para o ensino de alunos com deficiência: percepção de professores. 2006.215f. Dissertação (Mestrado em Educação). Universidade Estadual Paulista Júlio de Mesquita Filho/Marília, 2006.

MARQUEZINE, Maria Cristina. Formação de profissionais/professores de educação especial - deficiência mental e curso de pós-graduação lato sensu: Um estudo de caso. 2006. 244f. Tese (Doutorado em Educação). Universidade Estadual Paulista Júlio de Mesquita Filho/Marília, 2006.

GIROTO, Claudia Regina Mosca. A parceria entre o professor e o fonoaudiólogo: um caminho possível para a atuação com a linguagem escrita. 2006. 256f. Tese (Doutorado em 
Educação). Universidade Estadual Paulista Júlio de Mesquita Filho/Marília, 2006.

BALEOTTI, Luciana Ramos. Um estudo do ambiente educacional inclusivo: descrição das atitudes sociais em relação à inclusão e das relações interpessoais. 2006. 183f. Tese. (Doutorado em Educação). Universidade Estadual Paulista Júlio de Mesquita Filho/Marília, 2006.

OLIVEIRA, Franciane Teixeira de. Estudo do mobiliário escolar durante o desempenho de atividades lúdicas por alunos com paralisia cerebral espástica. 2007. 100f. Dissertação (Mestrado em Educação). Universidade Estadual Paulista Júlio de Mesquita Filho/Marília, 2006.

GUARDA, Nathália Silveira da. Caracterização dos enunciados de um aluno não-falante com paralisia cerebral durante o reconto de histórias com e sem o tabuleiro de comunicação suplementar. 2007. 158f. Dissertação (Mestrado em Educação). Universidade Estadual Paulista Júlio de Mesquita Filho/Marília, 2007.

HERCULIANI, Cristóvam Emílio. Desenvolvimento de um software de autoria para alunos deficientes não-falantes nas atividades de contos e recontos de histórias. 2007. 108f. Dissertação (Mestrado em Educação). Universidade Estadual Paulista Júlio de Mesquita Filho/Marília, 2007.

PAIVA, Paula do Carmo. Influência da textura do recurso pedagógico em atividade de encaixe realizada por alunos com paralisia cerebral. 2007. 104f. Dissertação (Mestrado em Educação). Universidade Estadual Paulista Júlio de Mesquita Filho/Marília, 2007.

PAULA, Raquel de. Desenvolvimento de um protocolo para avaliação de habilidades comunicativas de alunos não-falantes em ambiente escolar. 2007. 148f. Dissertação (Mestrado em Educação). Universidade Estadual Paulista Júlio de Mesquita Filho/Marília, 2007.

BRAGA, Maria Cecília Bergamo. O desenvolvimento da formação moral no sujeito autista: Um estudo exploratório. 2007. 116f. Tese (Doutorado em Educação). Universidade Estadual Paulista Júlio de Mesquita Filho/Marília, 2007.

TANAKA, Eliza Dieko Oshiro. O desenvolvimento de uma escala de atitudes sociais em relação ao trabalho da pessoa com deficiência. 2007. 198f Tese (Doutorado em Educação). Universidade Estadual Paulista Júlio de Mesquita Filho/Marília, 2007.

IMAMURA, Eliane Tie-Mi. Formação continuada do professor para uso de recursos de informática com alunos com deficiências físicas. 2008. 163f. Dissertação (Mestrado em Educação). Universidade Estadual Paulista Júlio de Mesquita Filho/Marília, 2008.

CARVALHO, Lia Raquel Pereira de Souza. Escolarização inclusiva de alunos com necessidades especiais: Um estudo de caso de um município paulista. 2008. 142f. Tese (Doutorado em Educação). Universidade Estadual Paulista Júlio de Mesquita Filho/Marília, 2008.

JUNIOR, Manoel Osmar Seabra. Estratégias de ensino e recursos pedagógicos para o ensino do aluno com deficiência visual na atividade física adaptada. 2008. 128f. Tese (Doutorado em Educação). Universidade Estadual Paulista Júlio de Mesquita Filho/Marília, 2008.

RISTER, Mara Cleusa Peixoto Assis. Inclusão escolar e gênero: o ambiente escolar como fator de influência no currículo social e acadêmico dos alunos das séries iniciais do Ensino Fundamental. 2008. 124f. Tese (Doutorado em Educação). Universidade Estadual Paulista Júlio de Mesquita Filho/Marília, 2008.

SILVA, Esther Giacomini. O perfil docente para a educação inclusiva - uma análise das atitudes, habilidades sociais e o perfil escolar inclusivo. 2008. 132f. Tese (Doutorado em Educação). Universidade Estadual Paulista Júlio de Mesquita Filho/Marília,2008.

Fonte: elaboração das autoras

Pelas referências das teses e dissertações presentes no quadro 1, observamos que, no âmbito do programa de pós-graduação em Educação da UNESP-Marília, o interesse pelas investigações das temáticas sobre: "Pesquisa e produção do 
conhecimento", "Adaptação à inclusão escolar e à formação de recursos humanos em Educação Especial”, “Adaptação pedagógica inclusiva/a ergonomia e o mobiliário adaptado", "Adaptação pedagógica inclusiva/Adaptação nas atividades e nos recursos", "Recursos alternativos e suplementares de comunicação em Educação Especial” e “Temáticas diversas", como podemos observar também por meio do Gráfico 1.

Grafico 1 - Teses e dissertações por eixo temático, desenvolvidas, entre 2005 e 2008, na linha de pesquisa Educação especial no Brasil

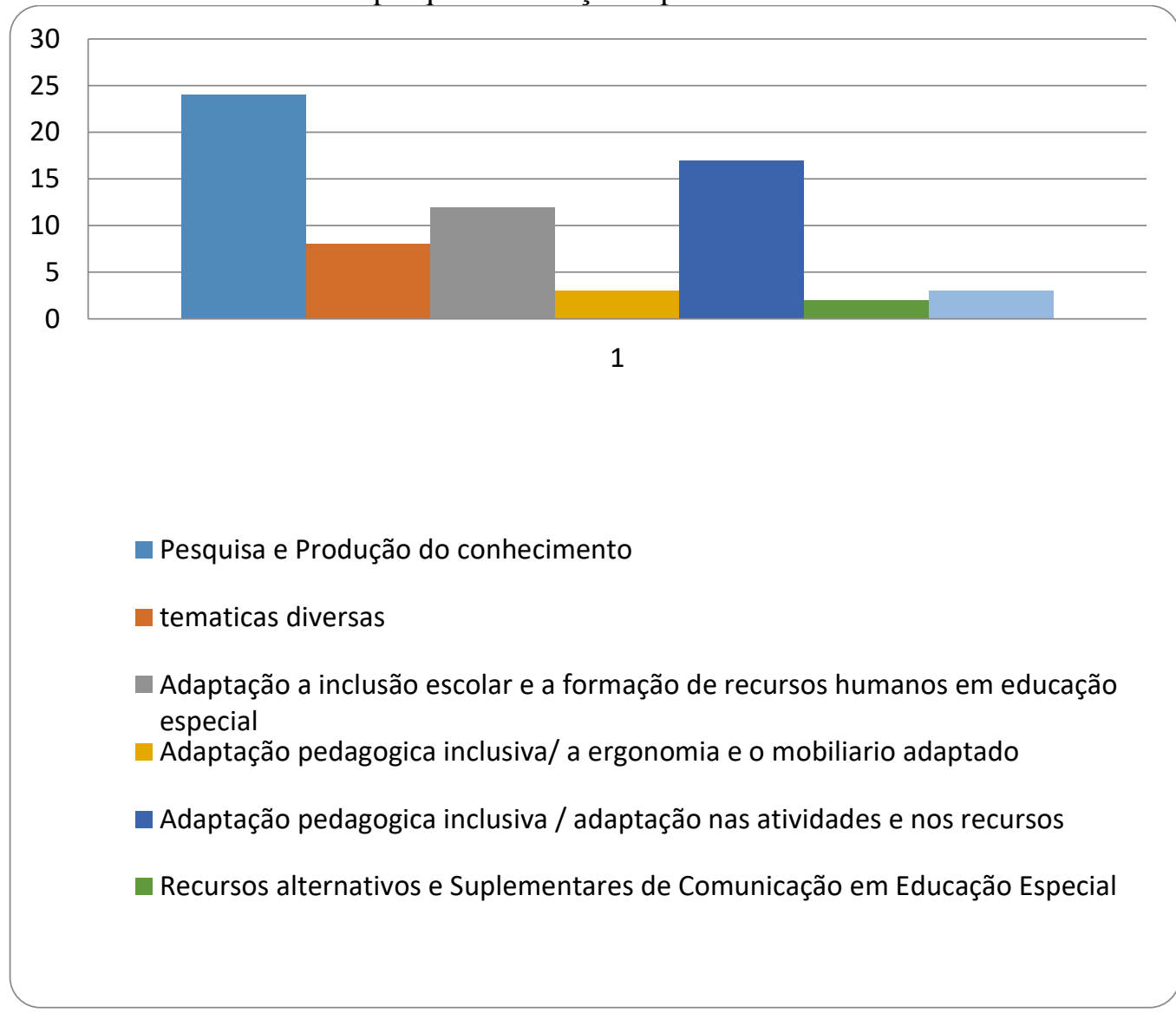

Fonte: elaboração das autoras

No eixo temático “Temáticas diversas”, como o próprio título informa, foi possível identificarmos temáticas que, apesar de importarem à educação, resultam, também, em dispersão dentro da linha de pesquisa quanto à ementa que a norteia, o que pode resultar uma avaliação da linha de pesquisa e do próprio programa nem sempre satisfatória e ou relevante para atendimento ao campo científico no qual tais pesquisas se inserem e nem ao atendimento às demandas sociais. Nessa temática se encaixam preocupações voltadas para doenças coronárias, programa preventivo de saúde, trabalho em classe hospitalar e trabalho com a terceira idade entre outras. A propósito, 
identificamos a dissertação de mestrado de Oliveira (2007), ${ }^{4}$ centrada na análise do desempenho de alunos com paralisia cerebral espástica, durante a realização de atividades em dois tipos de assentos e a sua relação com a distribuição de pressão.

No eixo temático “Adaptação pedagógica inclusiva/Adaptação a inclusão escolar e a formação de recursos humanos em Educação Especial" foi possível identificarmos a tese de doutorado de Marquezini (2006), voltada para desenvolver análise da relação entre a formação acadêmica e a atividade profissional tendo como contexto a avaliação do curso de especialização em Educação Especial - Deficiência mental da Universidade Estadual de Londrina, como uma alternativa para formação de professores. Os resultados da pesquisa mostraram que o curso teve uma influência relevante para a entrada, permanência e continuidade em trabalhos dos profissionais em organizações ou instituições e que a maior parte dos projetos de pesquisa desenvolvidos pelos discentes estiveram voltados para problemas suscitados pelo ensino de conteúdos de disciplinas da, então, Base Nacional Comum, desenvolvimento de habilidades e competência em alunos especiais. Também nesse eixo temático, Imamura (2008) apresentou sua dissertação com as preocupações voltadas na formação continuada do professor, para uso de recursos de informática com alunos do Ensino Médio, deficientes físicos, o que entendia contribuir para o processo de democratização do acesso à escola média nas décadas de 1980 e 1990 no Brasil. Ainda nesse eixo temático, identificamos a tese de doutorado de Silva (2008), desenvolvida com o objetivo de analisar as atitudes sociais dos professores de escolas comuns, juntamente com suas habilidades sociais frente à inclusão de alunos com necessidades educacionais especiais, e verificar se as diretrizes sobre a inclusão presentes nos documentos oficiais estavam em funcionamento nas escolas.

No eixo “Adaptação pedagógica inclusiva/Adaptações nas atividades e nos Recursos", identificamos a tese de doutorado de Bruno (2005), centrada na adaptação e adequação de instrumentos para estudar as funções visuais, as necessidades educacionais especiais e suas interrupções com o processo de desenvolvimento e aprendizagem, elaboração de instrumentos de avaliação pedagógica que permitiam ao professor especializado, em conjunto com a família, melhor compreensão, entre outros aspectos, das possibilidades, dos interesses, do desenvolvimento e, portanto, da aprendizagem das crianças deficientes visuais. Nesse eixo, também identificamos a

\footnotetext{
${ }^{4}$ Considerando-se que todas as teses e dissertações aqui apresentadas e discutidas já possuem suas
} referências no Quadro 1, não as replicamos ao final deste artigo em "REFERÊNCIAS". 
dissertação de Reganhan (2006) voltada para identificar a percepção do professor do ensino regular na cidade de Marília-SP sobre recursos e estratégias para o ensino do aluno deficiente inserido nas salas de aula. A pesquisadora concluiu que os professores participantes percebiam a necessidade de introduzir modificações, na aula, a fim de promover a aprendizagem desse aluno. Em (2007), Herculiani apresentou sua dissertação de mestrado, também identificada nesse eixo, em que o pesquisador buscou elaborar um software para inserir alunos acadêmicos não-falantes nas atividades dos alunos de sala regular. Paula (2007) desenvolveu sua dissertação de mestrado preocupada com o desenvolvimento de um protocolo para a avaliação de habilidades comunicativas de alunos não-falantes em ambientes escolares, como intitulou seu trabalho. Seabra Júnior (2008), também identificado nesse eixo temático, defendeu sua tese de doutorado em que buscou identificar, na literatura, proposições que descrevem estratégias de ensino e recursos pedagógicos propostos a alunos cegos ou com baixa visão. O pesquisador afirmou que o material produzido deverá servir como instrumento para formação de acadêmicos, para professores de instituições, professores de esportes adaptados e ainda para o uso diário de professores que atuam em meio à inclusão. Finalmente, não pudemos identificar a pesquisa de Audi (2006) nos eixos temáticos para análise, pois suas preocupações estiveram voltadas para a área médica, sem relação com a Educação Especial.

No eixo temático “Adaptação pedagógica inclusiva/Recursos alternativos e suplementares de comunicação em Educação Especial", foram identificadas apenas duas pesquisas. A primeira pesquisa é a de Muniz (2006) que realizou sua dissertação de mestrado, a partir das narrativas de um aluno com paralisia cerebral, que frequentava sala de atendimento educacional especializado, por meio de uso de recursos e estratégias de comunicação suplementar. Esse estudo ofertou contribuições para auxiliar o aluno na atividade de recontar historias e o professor na ampliação e na compreensão das formas de expressão, tanto verbal, quanto não-verbal do aluno. O segundo estudo identificado nesse mesmo eixo temático foi o de Guarda (2007). Em sua dissertação de mestrado, a pesquisadora visou a caracterização dos enunciados de um aluno nãofalante, também com paralisia cerebral, em situações de reconto de histórias, com e sem a utilização de um tabuleiro de comunicação suplementar.

No eixo temático "Alternativas pedagógicas inclusivas/pesquisa e produção do conhecimento em Educação Especial”, identificamos a dissertação de mestrado de Alves (2006) desenvolvida com o objetivo de identificar as modalidades expressivas e 
analisar as situações interativas durante o uso da pasta e do diário de comunicação por aluno não-falante, frente a diferentes interlocutores, durante a situação de jogo. Portanto pode identificar que os interlocutores são de grande importância para o uso de recursos suplementares e alternativos de comunicação com alunos não falantes. Também sobre a mesma temática, Sameshima (2006) desenvolveu sua dissertação de mestrado em busca de analisar habilidades expressivas de um grupo de alunos de alunos não-falantes durante atividades de jogos. Concluiu, afirmando que foi possível identificar que, durante a realização dos jogos, o grupo utilizou recursos de comunicação alternativa como figuras, fotos, objetos e pranchas para se comunicar, sendo que esses recursos foram facilitadores para a interação, compreensão e expressão do grupo. Nesse eixo temático identificamos a tese de doutorado de Giroto (2006) defendeu seu doutorado em busca de evidenciar que, a partir da parceria entre professor e fonoaudiólogo, espera-se que tais profissionais “[...] promovam a aprendizagem e contribuam para a edificação da escola inclusiva em vez de perpetuarem um modelo de atuação que reforça a exclusão social daqueles que não atendem às expectativas de seus professores e da escola." Baleotti (2006) defendeu sua tese de doutorado, afirmando que o meio social é um dos fatores criticamente relacionados ao caráter inclusivo da escola e, portanto, necessita ser permeado por atitudes e ações acolhedoras essenciais para a construção de um ambiente educacional inclusivo. Sobre esse aspecto, a pesquisadora evidenciou a "[...] limitação da escola para tornar-se um ambiente inclusivo e, ao mesmo tempo, buscou evidenciar as possibilidades de mudança de atitude sociais em direção à maior favorabilidade em relação à educação inclusiva." Braga (2007) defendeu teses de doutorado, abordando aspectos sobre o Desenvolvimento da formação moral do sujeito autista. Sobre isso, a pesquisadora afirmou que "[...] as dificuldades de interação e comunicação típicas do autismo, sua representação social marcada pela deficiência, além de intervenções escolares assistemáticas no campo da educação moral podem responder pelas características apresentadas pelo sujeito deste estudo." Carvalho (2008) defendeu seu doutorado com o objetivo de avaliar a política de educação inclusiva e ainda descrever o desempenho acadêmico e o espaço social ocupado por alunos que frequentavam classes do ensino comum, concomitante às salas de recurso. A pesquisadora afirmou que os princípios de inclusão estão assegurados legalmente, mas não sua operacionalização. Finalizando as pesquisas desse eixo temático, Rister (2008) defende sua tese de doutorado sobre aspectos do ambiente escolar na relação entre inclusão escolar e gênero e afirmou que, “[...] por meio dos comportamentos oriundos das ideias preconcebidas 
sobre [tais fatores], a escola perde a oportunidade de cumprir com seu papel de incentivar a prática da inclusão de meninos e meninas na escola e entre si mesmos."

Uma última dissertação de mestrado foi identificada, tanto no sobre "Inclusão escolar e a formação de recursos humanos em Educação Especial”, quanto no de "Pesquisa e Produção do conhecimento em Educação Especial". Trata-se da dissertação de Silva (2005) desenvolvida com o objetivo de analisar a percepção do professor de Educação Especial da rede municipal de Londrina a respeito de atuação e formação de educadores no contexto da comunicação alternativa. Nesse contexto, segundo a pesquisadora, a literatura tem demonstrado a necessidade de capacitação a respeito da área de Comunicação Alternativa. Os resultados indicaram a necessidade de programas e de pesquisas direcionados à formação dos educadores na área de Educação Especial, em virtude das necessidades específicas dos alunos deficientes. Igualmente, identificada em ambos os eixos, a dissertação de mestrado de Monteiro (2006) teve como objetivo identificar a existência de mudanças de concepções do professor do ensino regular que trabalha com alunos com deficiência, em relação à inclusão. Suas investigações indicaram não haver uma tendência definida na mudança de concepções e que a entrada, por si só, do aluno com deficiência no ensino regular não garantiu a mudança de concepções dos professores.

\section{Considerações finais}

Conforme os eixos temáticos proposto para nossas investigações, referente à produção de teses e dissertações da linha de pesquisa "Educação Especial no Brasil", do Programa de Pós-Graduação em Educação da UNESP/Câmpus de Marília, é possível afirmarmos que, no recorte temporal da pesquisa (2005-2008), os pesquisadores voltaram-se ao estudo das características das pessoas portadoras de necessidades especiais no contexto educativo numa perspectiva inclusiva, desde seus fundamentos até os aspectos ergonômicos e particulares do ensino nessa área, já acompanhando um movimento de discussão no meio acadêmico sobre tal questão, em resposta às exigências sócias postas.

Tal constatação vai ao encontro de uma terceira percepção que, segundo Melo e Silva (2016, p. 158), teria sido condutora das políticas públicas educacionais destinadas às pessoas com deficiência, que é a da “[...] sociedade inclusiva, que busca o rompimento de sistemas paralelos de Educação Especial." Segundo esses pesquisadores, 
com base em Freitas (2009) e Mazzotta (2011), atualmente essa percepção coexistiria com outras duas que a precederam: “1) assistencialista/caritativa, preocupado com o conforto e bem-estar; 2) modelo médico-terapêutico, com o predomínio das instituições especializadas.” Para esses pesquisadores, tais percepções “[...] coexistem, com suas marcas e papéis diferenciados, vivendo em embate no jogo das relações de forças dentro da sociedade civil, procurando influenciar as ações do Estado por meio das políticas públicas." (p. 158).

É possível afirmar que as preocupações recaem sobre os chamados saberes de referência da profissão docente para a docência na Educação Especial para a inclusão e ao lócus de produção de saberes.

Sobre o lócus de produção de saberes é possível reconhecer o conjunto de investigação centrada no papel do Ensino Superior, em nível de graduação e, sobretudo, nos nível de pós-graduação, de mestrados e doutorados, e programas de pós-graduação em educação. Portanto parece certo afirmar que os cursos e programas de pósgraduação em educação stricto sensu mestrado e doutorado buscam mediante o conjunto de suas áreas de concentração e linhas de pesquisa, legitimarem-se como lócus de produção de dado conhecimento, indicando demandas sociais e, portanto, fundamentando políticas públicas.

Assim, as pesquisas desenvolvidas na linha de pesquisa "Educação Especial no Brasil" do Programa de Pós-Graduação da UNESP de Marília, no período estudado, revelam uma tendência da pesquisa em Educação Especial, em diálogo com as demandas para uma Educação Especial numa perspectiva inclusiva.

Também e conforme foi possível afirmar, as pesquisas desenvolvidas na linha de pesquisa em estudo vão ao encontro da proposta de trabalho do Programa de PósGraduação da UNESP de Marilia, expressas na ementa da linha de pesquisa. Foi nesse contexto de apropriação do saber, do conhecimento, da cultura e da técnica, que analisamos as contribuições das teses e das dissertações da linha de pesquisa em estudo, cujos aspectos são importantes de serem retomados para se compreender os antecedentes históricos que embasaram a elaboração e implementação, em nosso país, da Política Nacional de Educação Especial na perspectiva da Educação Inclusiva, em 2008 .

\section{REFERÊNCIAS}


BELLOTTO, H. L. Os instrumentos de pesquisa no processo historiográfico. Anais..., Congresso Brasileiro de Arquivologia, 4, 1979, p. 133-147.

CASTRO, R. M. de. A produção acadêmica sobre formação de professores na PósGraduação em Educação da Unesp-Marília (1988-2008). 23 f. Projeto de Pesquisa (Triênio 2009-2011) - Faculdade de Filosofia e Ciências - Unesp/Marília, 2009a.

CASTRO, R. M. de. Teses e dissertações do programa de pós-graduação em educação da FFC-Unesp/Marília, produzidas entre 1992-2008. In: CASTRO, R. M. de. A PósGraduação em Educação da Faculdade de Filosofia e Ciências de Marília (1988-2008) e suas contribuições para a pós-graduação no Brasil: primeiros apontamentos. 605f.

Relatório Parcial de Pesquisa (Pós-Doutorado) - Fundação Carlos Chagas, São Paulo, 2009b.

CASTRO, R. M. de. Pós-Graduação em Educação da Faculdade de Filosofia e Ciências de Marília (1988-2008) e suas contribuições para a pós-graduação no Brasil. 23 f.

Projeto de Pesquisa (Pós-doutorado) - Fundação Carlos Chagas, São Paulo, 2009c.

CASTRO, R. M. de. A Pós-Graduação em Educação da Faculdade de Filosofia e Ciências de Marília (1988-2008) e suas contribuições para a pós-graduação no Brasil. 213f. Relatório Final de Pesquisa (Pós-Doutorado) - Fundação Carlos Chagas, São Paulo, 2010. disponível em:

http://www.fcc.org.br/pesquisa/estagios_pos_doutorais/pdf/pesquisa_rosane_final.pdf. Acesso em: 02 jul. 2010.

FREITAS, S. Direito à educação para pessoas com deficiência: considerações acerca das políticas públicas. In: BAPTISTA, C. R.; JESUS, D. M. de. (Org.). Avanços em políticas de inclusão: o contexto da Educação Especial no Brasil e em outros países. Porto Alegre: Mediação, 2009. p. 221-228.

MAZZOTTA, M. J. Educação Especial no Brasil: história e políticas públicas. 6 ed. São Paulo: Cortez, 2011.

MELO, D. C. F. de; SILVA, J. H. da. As políticas públicas da Educação Especial e a FENAPAEs sob a perspectiva gramsciana. Revista Ibero-Americana de Estudos em Educação, p. 151-164, abr., 2016. ISSN 1982-5587. DOI: 1021723/riaee.2016.v11.n1.p151.

NUNES, L. R. O. P. et al. Análise de dissertações e teses sobre Educação Especial nas áreas de Educação e Psicologia. In: MARQUEZINE, M. C; ALMEIDA, M. A.; OMOTE, S. Colóquios sobre pesquisa em Educação Especial. Londrina: Eduel, 2003. p. $137-152$.

NUNES, L. R. O. P.; FERREIRA, J. R.; MENDES, E. G. Teses e dissertações sobre Educação Especial: os temas investigados. In: MARQUEZINE, M. C; ALMEIDA, M. A.; OMOTE, S. Colóquios sobre pesquisa em Educação Especial. Londrina: Eduel, 2003. p. 113-136.

SILVA, M. R. Análise bibliométrica da produção científica docente do Programa de Pós-Graduação em Educação Especial/UFSCar: 1998-2003. Dissertação 
(Mestrado em Educação Especial) - Universidade Federal de São Carlos, São Carlos, 2004.

\section{Como referenciar este artigo}

SANTANA, Maria Silvia Rosa; CASTRO, Rosane Michelli de.; LIMA, Elieuza Aparecida de. A produção acadêmico-científica do Programa de Pós-Graduação em Educação da UNESP/Marília-SP e a Política Pública Nacional de Educação Especial no Brasil: aspectos históricos. Revista on line de Política e Gestão Educacional, Araraquara, v. 22, n. esp. 2, p. 748-762, 2018. E-ISSN:1519-9029. DOI: 10.22633/rpge.unesp.v22.nesp2.dez.2018.11910

Submetido em: 20/07/2018

Aprovado em: 10/11/2018 